\title{
Kinetic Studies of the Reaction of Atomic Chlorine with
}

\section{Chlorobenzene}

\author{
Yide Gao and Paul Marshall* \\ Department of Chemistry and Center for Advanced Scientific Computing \\ and \\ Modeling (CASCaM), University of North Texas \\ 1155 Union Circle \#305070, Denton, Texas 76203-5017 \\ *marshall@unt.edu
}

\begin{abstract}
The rate constant $k_{1}$ for $\mathrm{Cl}+\mathrm{C}_{6} \mathrm{H}_{5} \mathrm{Cl} \rightarrow$ products has been studied via the pulsed laser photolysis - time-resolved resonance fluorescence technique over 710 - $1030 \mathrm{~K}$. The results may be summarized as $k_{1}=(1.36 \pm 0.47) \times 10^{-10} \mathrm{~cm}^{3}$ molecule $\mathrm{s}^{-1} \exp \{-$ $\left.(42.5 \pm 2.5) \mathrm{kJ} \mathrm{mol}^{-1} / \mathrm{RT}\right\}$. The quoted uncertainties are $\pm 1 \sigma$, and the $95 \%$ confidence limit for $k_{1}$ is $\pm 21 \%$. The major pathway is proposed to be formation of $\mathrm{HCl}$ and chlorophenyl radicals. Density functional calculations suggest the most favorable product is 3-chlorophenyl arising from attack meta to the $\mathrm{C}-\mathrm{Cl}$ bond.
\end{abstract}




\section{Introduction}

Chlorobenzene is a model compound for analysis of destruction of chlorinated aromatic molecules by combustion, where avoidance of formation of toxic chlorinated dibenzodioxins is a significant issue [1-5]. Burfeindt and Homann showed that $\mathrm{C}_{6} \mathrm{H}_{5} \mathrm{Cl}$ is a major initial product in benzene flames doped with chlorine compounds, and that in turn $\mathrm{C}_{6} \mathrm{H}_{5} \mathrm{Cl}$ is transformed to further products [6]. We have proposed the reaction

$$
\mathrm{Cl}+\mathrm{C}_{6} \mathrm{H}_{5} \mathrm{Cl} \rightarrow \text { products }
$$

may lead to chlorophenyl radicals which could react with chlorobenzene in part via Hatom displacement [7]. These steps can form part of a combustion chain reaction where $\mathrm{H}$ atoms then consume chlorobenzene by abstraction of $\mathrm{Cl}$. The present study is part of an overall effort to quantify the high-temperature chemistry of chlorobenzene.

Reaction 1 has been studied previously in the context of atmospheric chemistry, via relative rate methods. Sokolov et al. determined an upper limit of $2.5 \times 10^{-16} \mathrm{~cm}^{3}$ molecule $\mathrm{e}^{-1} \mathrm{~s}^{-1}$ for $\mathrm{HCl}$ formation at room temperature [8]. This is below a prior measured total rate constant of $9.8 \times 10^{-16} \mathrm{~cm}^{3}$ molecule $^{-1} \mathrm{~s}^{-1}$ by Shi and Bernhard [9]. A potential reaction path under these conditions is formation of dichlorocyclohexadienyl radicals by addition. There have been no measurements at elevated temperatures. Here we use the laser flash photolysis - resonance fluorescence technique to obtain the first kinetic data at 710 - $1030 \mathrm{~K}$ for the total rate constant $k_{1}$, and apply density functional theory to assess likely product channels. 


\section{Methodology}

Chlorobenzene (Mallinckrodt, 99.9\% purity AR grade) was degassed via two freezepump-thaw cycles at $77 \mathrm{~K}$ and then distilled twice from room temperature. In these distillations the middle $80 \%$ was trapped at $77 \mathrm{~K}$. Details of the apparatus have been given elsewhere $[7,10]$. Briefly, atomic $\mathrm{Cl}$ is formed by pulsed laser photolysis of a small fraction of chlorobenzene at $193 \mathrm{~nm}$. We have determined an absorption cross section of $(9.62 \pm 0.14) \times 10^{-18} \mathrm{~cm}^{2}$ molecule ${ }^{-1}$ which is temperature-independent over $300-500 \mathrm{~K}$, and the quantum yield for dissociation to $\mathrm{C}_{6} \mathrm{H}_{5}+\mathrm{Cl}$ is unity [11,12]. For the purpose of estimating the initial concentrations of $\mathrm{Cl}$ and $\mathrm{C}_{6} \mathrm{H}_{5}$ we assume these properties of $\mathrm{C}_{6} \mathrm{H}_{5} \mathrm{Cl}$ do not vary with temperature over $700-1000 \mathrm{~K}$. Deviations will not be critical because we use pseudo-first-order conditions and knowledge of absolute radical concentrations is not required. The concentration of $\mathrm{Cl}$ is probed by time-resolved resonance fluorescence at 130 - $140 \mathrm{~nm}$, excited by a microwave discharge lamp and monitored with a solar-blind photomultiplier tube operated in a photon-counting mode with signal averaging in a multi-channel scaler. Calcium fluoride optics block any Hatom radiation. Experiments were conducted in a large excess of Ar bath gas (Air Liquide, 99.9997\%), which thermalized the reactants and slowed diffusion of radicals out of the observation zone defined by the intersection of the beams of photolysis and probe radiation.

$$
\begin{aligned}
& \text { Under the condition }\left[\mathrm{C}_{6} \mathrm{H}_{5} \mathrm{Cl}\right] \gg[\mathrm{Cl}] \text {, we may write } \\
& \mathrm{d}[\mathrm{Cl}] / \mathrm{dt}=-k_{1}\left[\mathrm{C}_{6} \mathrm{H}_{5} \mathrm{Cl}\right][\mathrm{Cl}]-k_{d i f f}[\mathrm{Cl}]=-k_{p s 1}[\mathrm{Cl}]
\end{aligned}
$$

where $k_{\text {diff }}$ accounts for loss of $\mathrm{Cl}$ by diffusion and by any reaction with photolysis fragments of $\mathrm{C}_{6} \mathrm{H}_{5} \mathrm{Cl}$. These processes were found to be sensibly first-order. $k_{p s 1}$ is the 
effective pseudo-first-order decay coefficient, and is derived via non-linear fitting to the exponential decay profiles such as that shown in the inset of Fig. 1. Plots of $k_{p s 1}$ vs. [ $\left.\mathrm{C}_{6} \mathrm{H}_{5} \mathrm{Cl}\right]$ like those shown in Fig. 1 yield $k_{1}$ and its uncertainty from the slope, and the intercept corresponds to $k_{\text {diff. }}$. As expected for a process dominated by diffusion, $k_{\text {diff }}$ increased with increasing $\mathrm{T}$ and decreased with increasing total pressure $\mathrm{P}$, as can be seen in Fig. 1.

\section{Results}

Table 1 summarizes 21 measurements of $k_{1}$ over $710-1030$ K. For each measurement data were typically obtained at 6 values of $\left[\mathrm{C}_{6} \mathrm{H}_{5} \mathrm{Cl}\right]$ up to $\left[\mathrm{C}_{6} \mathrm{H}_{5} \mathrm{Cl}\right]_{\max }$. The listed uncertainties are the statistical standard deviations of the slopes of plots like Fig. 1. An important check is that there is no consistent variation with the initial $\mathrm{Cl}$ concentration, as determined from the laser photolysis energy $F$ and the concentration and UV crosssection of chlorobenzene. This confirms that pseudo-first-order conditions were attained and that reaction 1 was successfully isolated from secondary chemistry. Very low laser photolysis energies, below $50 \mu \mathrm{J}$, were used to provide low initial radical concentrations, in the range (1-13) x $10^{10}$ molecule $\mathrm{cm}^{-3}$. Consistent with the lack of influence of photolytic or reaction products, if $\mathrm{Cl}$ is removed by reaction with $\mathrm{C}_{6} \mathrm{H}_{5}$ or chlorophenyl with a rate constant of $10^{-10} \mathrm{~cm}^{3}$ molecule ${ }^{-1} \mathrm{~s}^{-1}$, then the contribution of $\leq 13 \mathrm{~s}^{-1}$ to $k_{p s 1}$ is negligible. The independence of $k_{1}$ from the pressure $\mathrm{P}$ and the average residence time of the reaction mixture in the heated cell, $\tau_{\text {res}}$, observed previously [7], indicate that thermal decomposition of $\mathrm{C}_{6} \mathrm{H}_{5} \mathrm{Cl}$ is not significant in our apparatus. This is in accord with the 
work of Ritter et al. who determined a $\mathrm{C}_{6} \mathrm{H}_{5} \mathrm{Cl}$ dissociation rate of less than $10^{-4} \mathrm{~s}^{-1}$ at $1070 \mathrm{~K}[4]$.

The data for reaction 1 are plotted in Arrhenius form on Fig. 2. A linear fit, weighted according to the statistical uncertainties listed in Table 1 and $\sigma_{\mathrm{T}} / \mathrm{T}=2 \%$, may be expressed as

$$
k_{1}=(1.36 \pm 0.47) \times 10^{-10} \mathrm{~cm}^{3} \text { molecule } \mathrm{e}^{-1} \mathrm{~s}^{-1} \exp \left\{-(42.5 \pm 2.5) \mathrm{kJ} \mathrm{mol}^{-1} / \mathrm{RT}\right\}
$$

over $710-1030 \mathrm{~K}$. The quoted uncertainties are $\pm 1 \sigma$ for the pre-exponential factor and the activation energy $E_{\mathrm{a}}$. Consideration of the covariance of $-102.8 \mathrm{~K}^{-1}$ yields statistical $2 \sigma$ error limits of up to $20 \%$ in $k_{1}$. Combination in quadrature with propagated instrumental uncertainties of $~ 5 \%$ yields a $95 \%$ confidence limit of $\pm 21 \%$ for $k_{1}$.

\section{Discussion}

Extrapolation of eq. 3 to $298 \mathrm{~K}$ yields $5 \times 10^{-18} \mathrm{~cm}^{3}$ molecule $\mathrm{e}^{-1} \mathrm{~s}^{-1}$ with a $2 \sigma$ uncertainty of a factor of 3. This indicates that the determination of Shi et al. [9], which is 200 times larger, is likely too high. This is in accord with arguments of Sokolov et al. [8] concerning the reaction

$$
\mathrm{Cl}+\mathrm{C}_{6} \mathrm{H}_{6} \rightarrow \text { products }
$$

who noted that impurities or secondary chemistry might have been important in earlier work. Sokolov et al. observed no formation of $\mathrm{HCl}$ and set an upper limit of $k_{1}<2.5 \mathrm{x}$ $10^{-16} \mathrm{~cm}^{3}$ molecule $\mathrm{s}^{-1}$, which agrees with extrapolation of our data. We may also compare $k_{1}$ with our previous measurements of the analogous reaction 4 [10]. The latter is faster by about a factor of 3 at $700 \mathrm{~K}$ and a factor of 2 at $1000 \mathrm{~K}$. 
Next we consider possible product channels. Cui et al. [3] showed that, at $1050 \mathrm{~K}$, $\mathrm{H}$ atoms can be displaced by atomic $\mathrm{Cl}$ with a rate constant below $10^{-16} \mathrm{~cm}^{3}$ molecule $\mathrm{s}^{-1}$ , which is too slow to contribute significantly to the Cl consumption we observed. Density functional theory calculations outlined below indicated no barrier to Cl-atom addition, which suggests that when thermodynamically favored (at low temperatures) addition may be a fast process. By analogy with $\mathrm{Cl}$ addition to benzene [8], adduct formation between $\mathrm{Cl}$ and $\mathrm{C}_{6} \mathrm{H}_{5} \mathrm{Cl}$ will be thermodynamically unfavorable at elevated temperatures. The estimated thermochemistry for adduct formation between $\mathrm{Cl}$ and benzene [8] implies that, if similar interactions occur between $\mathrm{Cl}$ and chlorobenzene, then under our conditions less than 1 part in $10^{6}$ of atomic $\mathrm{Cl}$ would be bound at equilibrium, and thus formation of dichlorocyclohexadienyl may be neglected here. The corresponding lifetime for this adduct at $700 \mathrm{~K}$ is less than $20 \mathrm{~ns}$. A third possible pathway is $\mathrm{Cl}$ abstraction to form phenyl $+\mathrm{Cl}_{2}$. The computed reaction enthalpy is +163 $\mathrm{kJ} \mathrm{mol}^{-1}$ at $0 \mathrm{~K}$, so $\mathrm{Cl}_{2}$ formation may be ruled out.

$\mathrm{H}$-abstraction to form $\mathrm{HCl}$ and chlorophenyl radicals is a plausible pathway at higher temperatures because for the analogous $\mathrm{Cl}+$ benzene reaction the endothermicity

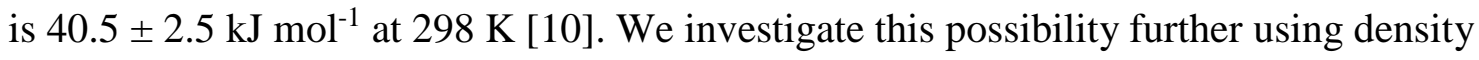
functional theory, with the MPWB1K functional and the MG3 basis set [13]. These calculations were carried out with the Gaussian 03 program suite [14]. There are three sites for $\mathrm{Cl}$ attack leading to $\mathrm{HCl}$ : ortho, meta and para to the $\mathrm{C}-\mathrm{Cl}$ bond. Qualitatively similar reaction paths were obtained in each case. A planar abstraction transition state (TS) lies below the energy of chlorophenyl radical plus $\mathrm{HCl}$. Between the TS and final products there is a local minimum on the classical potential energy surface (i.e., the PES 
without zero-point vibrational energy, ZPE), where the $\mathrm{HCl}$ is approximately perpendicular to the aromatic ring and the $\mathrm{H}$ atom points towards the ring. A second planar conformation has the radical center on the phenyl ring pointing towards the $\mathrm{H}$ end of the $\mathrm{HCl}$ molecule. As an example, Figure 3 shows the structures for attack at the meta position. With the inclusion of ZPE the $0 \mathrm{~K}$ enthalpies of the possible adducts lie within \pm $2 \mathrm{~kJ} \mathrm{~mol}^{-1}$ of the TSs, which indicates a fairly flat PES in this region and that the bond strengths of the apparent adducts are very small, if they are bound at all. The density functional results are summarized in Table 2 and full details are given in the Supplementary Material.

Quantitative kinetic analysis of this kind of PES requires RRKM or modified transition state theory approaches $[15,16]$, but three qualitative conclusions may be drawn here. The first is that the most favorable path, both kinetically and thermochemically, is meta attack, which has a reaction path degeneracy of two. The next most favorable path is para attack, which has a slightly higher barrier and whose contribution will be further reduced by its reaction path degeneracy of one. Ortho attack is the least favorable pathway.

The second conclusion is that, because the energy of the TS lies below that of the products, a negative activation energy is likely for the reverse reaction of chlorophenyl radicals with $\mathrm{HCl}$. This prediction is consistent with the negative temperature dependence we observed for the reaction of $\mathrm{C}_{6} \mathrm{H}_{5}$ with $\mathrm{HCl}$ [10]. If $k_{-1}$ exhibits $\mathrm{E}_{\mathrm{a}}<0$, then $\mathrm{E}_{\mathrm{a}}$ for $k_{1}$ will be somewhat less than the endothermicity [17].

Third, the computed $0 \mathrm{~K}$ reaction enthalpy for meta attack is close to the value of $38.2 \mathrm{~kJ} \mathrm{~mol}^{-1}$ computed for $\mathrm{Cl}+\mathrm{C}_{6} \mathrm{H}_{6} \rightarrow \mathrm{C}_{6} \mathrm{H}_{5}+\mathrm{HCl}$. If the C-H bond reactivity is 
similar at the 6 positions in benzene and the 2 meta positions of chlorobenzene, then a ratio of reactivity of 3:1 would be likely. With smaller reactivity contributions from the para and ortho positions, the expected ratio of somewhat less than 3 to 1 is in line with that observed.

\section{Conclusions}

Rate constants for the reaction of $\mathrm{Cl}$ atoms with chlorobenzene have been obtained over about $710-1030 \mathrm{~K}$, and this reaction is found to be a factor of 2-3 slower than the analogous reaction of benzene. The most likely pathways involve $\mathrm{H}$ abstraction, via transition states lower in energy than the final products, to yield $\mathrm{HCl}$ and chlorophenyl radicals. Density functional calculations suggest the most favorable of these is the 3chlorophenyl radical, produced by attack at the C-H bond meta to the C-Cl bond.

\section{Acknowledgments}

This work was supported by the R.A. Welch Foundation (Grant B-1174) and the UNT Faculty Research Fund. Computational facilities were purchased through NSF grant CHE-0741936. 


\section{References}

[1] J. A. Manion, P. Mulder and R. Louw, Environ. Sci. Technol. 19 (1985) 280.

[2] J. A. Manion and R. Louw, J. Phys. Chem. 94 (1990) 4127.

[3] J. P. Cui, Y. Z. He and W. Tsang, J. Phys. Chem. 93 (1989) 724.

[4] E. R. Ritter, J. W. Bozzelli and A. M. Dean, J. Phys. Chem. 94 (1990) 2493.

[5] B. R. Stanmore, Combust. Flame 136 (2004) 398.

[6] J. Burfeindt and K.-H. Homann, Chemosphere 42 (2001) 439.

[7] Y. Gao and P. Marshall, Proc. Combust. Inst. 32 (2009) 351.

[8] O. Sokolov, M. D. Hurley, T. J. Wallington, E. W. Kaiser, J. Platz, O. J. Nielsen, F. Berho, M.-T. Rayez and R. Lesclaux, J. Phys. Chem. A 102 (1998) 10671.

[9] J. Shi and M. Bernhard, Int. J. Chem. Kinet. 29 (1997) 349.

[10] I. M. Alecu, Y. Gao, P.-C. Hsieh, J. P. Sand, A. Ors, A. McLeod and P. Marshall, J. Phys. Chem. A 111 (2007) 3970.

[11] T. Ichimura and Y. Mori, J. Chem. Phys. 58 (1973) 288.

[12] T. Ichimura, Y. Mori, H. Shinohara and N. Nishi, Chem. Phys. Lett. 189 (1994) 117.

[13] Y. Zhao and D. G. Truhlar, J. Phys. Chem. A 108 (2004) 6908.

[14] M. J. Frisch, G. W. Trucks, H. B. Schlegel, G. E. Scuseria, M. A. Robb, J. R. Cheeseman, J. J. A. Montgomery, T. Vreven, K. N. Kudin, J. C. Burant, J. M. Millam, S. S. Iyengar, J. Tomasi, V. Barone, B. Mennucci, M. Cossi, G. Scalmani, N. Rega, G. A. Petersson, H. Nakatsuji, M. Hada, M. Ehara, K. Toyota, R. Fukuda, J. Hasegawa, M. Ishida, T. Nakajima, Y. Honda, O. Kitao, H. Nakai, M. Klene, X. Li, J. E. Knox, H. P. Hratchian, J. B. Cross, C. Adamo, J. Jaramillo, 
R. Gomperts, R. E. Stratmann, O. Yazyev, A. J. Austin, R. Cammi, C. Pomelli, J. W. Ochterski, P. Y. Ayala, K. Morokuma, G. A. Voth, P. Salvador, J. J. Dannenberg, V. G. Zakrzewski, S. Dapprich, A. D. Daniels, M. C. Strain, O.

Farkas, D. K. Malick, A. D. Rabuck, K. Raghavachari, J. B. Foresman, J. V. Ortiz, Q. Cui, A. G. Baboul, S. Clifford, J. Cioslowski, B. B. Stefanov, G. Liu, A. Liashenko, P. Piskorz, I. Komaromi, R. L. Martin, D. J. Fox, T. Keith, M. A. AlLaham, C. Y. Peng, A. Nanayakkara, M. Challacombe, P. M. W. Gill, B. Johnson, W. Chen, M. W. Wong, C. Gonzalez and J. A. Pople, Gaussian 03. Gaussian, Pittsburgh, 2003.

[15] D. M. Golden, J. Phys. Chem. 83 (1979) 108.

[16] L. N. Krasnoperov, J. Peng and P. Marshall, J. Phys. Chem. A 110 (2006) 3110.

[17] Y. Gao, I. M. Alecu, P.-C. Hsieh, B. P. Morgan, P. Marshall and L. N. Krasnoperov, J. Phys. Chem. A 110 (2006) 6844. 
Table 1. Summary of rate constant measurements for $\mathrm{Cl}+\mathrm{C}_{6} \mathrm{H}_{5} \mathrm{Cl} \rightarrow \mathrm{C}_{6} \mathrm{H}_{5}+\mathrm{HCl}$

\begin{tabular}{|c|c|c|c|c|c|c|c|c|c|c|}
\hline \multirow{2}{*}{$\begin{array}{c}\mathrm{T}, \\
\mathrm{K} \\
713\end{array}$} & \multirow{2}{*}{$\begin{array}{c}\tau_{\text {res }}, \\
\mathrm{s} \\
2.0\end{array}$} & \multirow{2}{*}{$\begin{array}{c}\begin{array}{c}\mathrm{F}, \\
\mathrm{mJ}\end{array} \\
0.046\end{array}$} & \multirow{2}{*}{$\begin{array}{c}\text { P, } \\
\text { mbar }\end{array}$} & \multicolumn{3}{|c|}{$\begin{array}{c}{\left[\mathrm{C}_{6} \mathrm{H}_{5} \mathrm{Cl}\right]_{\max }} \\
10^{14} \text { molecule } \\
\mathrm{cm}^{-3}\end{array}$} & \multirow{2}{*}{$\begin{array}{c}{[\mathrm{Cl}]_{0, \max },} \\
\begin{array}{c}10^{10} \\
\text { molecule } \\
\mathrm{cm}^{-3}\end{array} \\
2.5\end{array}$} & \multicolumn{3}{|c|}{$\begin{array}{c}k_{1} \pm \sigma_{\mathrm{k} 1},{ }^{\mathrm{a}} \\
10^{-13} \mathrm{~cm}^{3} \text { molecule }^{-1} \mathrm{~s}^{-1}\end{array}$} \\
\hline & & & & 1.88 & \pm & 0.08 & & 1.43 & \pm & 0.07 \\
\hline 713 & 2.0 & 0.017 & 159 & 1.88 & \pm & 0.08 & 2.5 & 0.87 & \pm & 0.07 \\
\hline 713 & 2.0 & 0.043 & 159 & 1.88 & \pm & 0.08 & 6.3 & 1.32 & \pm & 0.06 \\
\hline 812 & 0.3 & 0.017 & 71 & 2.35 & \pm & 0.09 & 2.5 & 2.17 & \pm & 0.19 \\
\hline 813 & 0.5 & 0.010 & 73 & 3.19 & \pm & 0.13 & 1.5 & 2.35 & \pm & 0.15 \\
\hline 813 & 0.2 & 0.012 & 29 & 1.53 & \pm & 0.06 & 1.8 & 2.18 & \pm & 0.19 \\
\hline 813 & 0.2 & 0.007 & 29 & 1.53 & \pm & 0.06 & 1.0 & 2.52 & \pm & 0.16 \\
\hline 814 & 0.3 & 0.010 & 76 & 1.70 & \pm & 0.07 & 1.5 & 2.31 & \pm & 0.17 \\
\hline 914 & 0.2 & 0.007 & 69 & 1.69 & \pm & 0.07 & 1.0 & 3.33 & \pm & 0.21 \\
\hline 915 & 0.2 & 0.090 & 72 & 1.39 & \pm & 0.06 & 13.3 & 5.41 & \pm & 0.25 \\
\hline 915 & 0.2 & 0.040 & 72 & 1.39 & \pm & 0.06 & 5.9 & 4.98 & \pm & 0.23 \\
\hline 915 & 0.2 & 0.026 & 36 & 1.34 & \pm & 0.05 & 3.8 & 6.11 & \pm & 0.35 \\
\hline 915 & 0.2 & 0.013 & 36 & 1.34 & \pm & 0.05 & 1.9 & 4.55 & \pm & 0.39 \\
\hline 1025 & 0.4 & 0.020 & 72 & 1.90 & \pm & 0.08 & 3.0 & 7.14 & \pm & 0.51 \\
\hline 1025 & 0.4 & 0.009 & 72 & 1.90 & \pm & 0.08 & 1.3 & 8.79 & \pm & 0.49 \\
\hline 1025 & 0.2 & 0.019 & 75 & 1.37 & \pm & 0.05 & 2.7 & 9.95 & \pm & 0.62 \\
\hline 1025 & 0.2 & 0.017 & 71 & 1.25 & \pm & 0.05 & 2.5 & 10.60 & \pm & 0.85 \\
\hline 1026 & 0.2 & 0.017 & 44 & 1.55 & \pm & 0.06 & 2.5 & 12.40 & \pm & 0.65 \\
\hline 1026 & 0.2 & 0.036 & 44 & 1.55 & \pm & 0.06 & 5.3 & 11.50 & \pm & 0.71 \\
\hline 1027 & 0.2 & 0.028 & 28 & 1.33 & \pm & 0.05 & 4.1 & 9.91 & \pm & 0.65 \\
\hline 1027 & 0.2 & 0.010 & 28 & 1.59 & \pm & 0.06 & 1.5 & 7.56 & \pm & 0.61 \\
\hline
\end{tabular}

${ }^{\mathrm{a}}$ Statistical uncertainty in plot of $\mathrm{k}_{\mathrm{ps} 1} \mathrm{vs}\left[\mathrm{C}_{6} \mathrm{H}_{5} \mathrm{Cl}\right]$. 
Table 2. Relative enthalpies at $0 \mathrm{~K}_{\text {in }} \mathrm{kJ} \mathrm{mol}^{-1}$ for stationary points in the $\mathrm{C}_{6} \mathrm{H}_{5} \mathrm{Cl}+\mathrm{Cl}$

$\rightarrow \mathrm{C}_{6} \mathrm{H}_{4} \mathrm{Cl}+\mathrm{HCl}$ system, based on MPWB1K/MG3 calculations and including zeropoint vibrational energy scaled by a standard factor of 0.9567 and a $3.5 \mathrm{~kJ} \mathrm{~mol}^{-1}$ spinorbit correction to the energy of atomic $\mathrm{Cl}$.

\begin{tabular}{|c|c|c|c|c|}
\hline pathway & TS & $\begin{array}{c}\text { adduct } \\
\text { (perpendicular) }\end{array}$ & $\begin{array}{c}\text { adduct } \\
\text { (planar) }\end{array}$ & $\begin{array}{c}\text { chlorophenyl }+ \\
\text { HCl }\end{array}$ \\
\hline ortho attack & 41.7 & 40.1 & 41.7 & 45.7 \\
\hline meta attack & 32.9 & 33.5 & 34.6 & 39.1 \\
\hline para attack & 34.6 & 36.0 & 36.6 & 41.9 \\
\hline
\end{tabular}




\section{Figure captions}

Fig. 1

Example plots of pseudo-first-order decay coefficient vs. chlorobenzene concentration at $713 \mathrm{~K}$ and 159 mbar Ar bath gas (circles) and $1026 \mathrm{~K}$ and 44 mbar Ar bath gas (squares). The error bars represent $\pm 1 \sigma$. The inset shows the decay of fluorescence photon counts corresponding to the filled circle.

\section{Fig. 2}

Arrhenius plot of rate constants for $\mathrm{Cl}+\mathrm{C}_{6} \mathrm{H}_{5} \mathrm{Cl}$. Error bars represent $\pm 1 \sigma$ statistical uncertainties.

\section{Fig. 3}

Density functional theory geometries for structures along the reaction path for abstraction of $\mathrm{H}$ from the meta position in chlorobenzene. From top to bottom: transition state, perpendicular adduct between chlorophenyl and $\mathrm{HCl}$, planar conformation of the adduct. 